\title{
Buildup and wash-off dynamics of organic pollutants, nutrients and coliforms on impervious surfaces: An experiment
}

\author{
Zhenren Guo, Hj Mohd Khairuldini bin Hj Metali , Shahriar Shams, Asmaal \\ Muizz Sallehhin bin HM Sultan
}

Faculty of Engineering, Universiti Teknologi Brunei, Tungku Highway, Gadong, BE 1410, Brunei Darussalam

\begin{abstract}
Simulated rainfall experiments were conducted at sites representing parking lots, restaurants and residential blocks in a typical commercial complex of a humid tropical city to investigate wash-off and buildup processes of $\mathrm{BOD}_{5}$, ammonia, phosphate, fecal coliforms and total coliforms. It was found that the mass buildup of the studied pollutants is basically independent of the type of land use in the same area. The experiment further revealed that the maximum concentrations of the pollutants, $C_{\mathrm{m}}$, do not necessarily occur at $t=0$. Instead, they more occurred between $t=5-10$ minutes after the beginning of the wash-off process. Thus, the exponential decay function can well replicate the pollutographs only from $C=C_{\mathrm{m}}$. Accordingly, wash-off coefficients ranging from $0.08-0.15 \mathrm{~mm}^{-1}$ respectively for $\mathrm{BOB}_{5}$, nutrients and coliforms were suggested based on the experimental data. Parameters of the exponential buildup function suggested by Novotny were also identified for $\mathrm{BOD}_{5}$, ammonia, phosphate, respectively, using the experimental data, whereas growths of fecal and total coliforms were replicated by the logistic growth model. The parameters obtained for the buildup functions are deemed to be applicable to the humid tropical urban areas similar to where the experiment was conducted. The findings of this study are useful when the pollutant buildup and wash-off dynamics are introduced into urban stormwater quality models.
\end{abstract}

Keywords: wash-off, buildup, pollutants, impervious surfaces

\section{Introduction}

Pollutants built up over an antecedent dry period on impervious urban surfaces and then washed off by a rainfall event are the major source of rainwater pollution. The polluted rainwater can then further result in pollution to receiving waters adjacent to the urban areas during and after the rainfall event. Understanding buildup and wash-off dynamics of pollutants on urban surfaces are of the essence in order to estimate pollutant loads from this non-point source. Buildup and wash-off dynamics also provide basic equations and parameters needed by various models for urban storm water quality prediction. This prediction will help design and operation of the urban water infrastructures for stormwater pollution control or rainwater harvest.

A range of studies were conducted to understand pollutant buildup and wash-off process. This includes mathematical description and experimental identification. Novotny [1] suggested a buildup function that can take into account of both daily accumulation and erosion rate over antecedent dry weather period (ADWP or ADP), whereas the typical wash-off function means that a pollutant wash-off rate is proportional to the remaining mass of the pollutant on the ground surface and the runoff flow rate [2]. Several empirical functions describing pollutant buildup and wash-off process were provided in SWMM model for users' selection [3]. Parameters in the above-mentioned functions should normally be determined by experiments. These parameters firstly vary with species of pollutants. Secondly, they can

\footnotetext{
* Manuscript received December 8, 2018; revised May 22, 2019.

Corresponding author. Tel.: +673-2461020-5513; E-mail address: guo.zhenren@utb.edu.bn.

doi: $10.12720 /$ sgce.8.5.529-538
} 
be different for each land use and features of the ground surfaces. Furthermore, they are influenced by many other factors such as sunlight, temperature and humidity of the atmosphere, wind, size distribution of particles on the ground surface, and of course human activities. Therefore, an experiment can usually look at certain types of pollutants under certain conditions. Wash-off of TSS and heavy metals firstly drew the attention of researchers since TSS and heavy metals as inorganic pollutants are not degradable, and TSS is believed to be a carrier of some other pollutants. Egodawatta et al [4] applied simulated rainfalls on urban road surfaces and confirmed that the wash-off process of TSS generally follows the exponential decay function but to which a "capacity factor" should be added. They applied the same methodology also to the roof surface and further validated their previous findings [5]. Wicke et al [6] studied both of buildup and wash-off process of TSS and heavy metals on impermeable urban surfaces and certified that the saturation equation can well fit the experimental data of pollutant buildup. In a later wash-off experiment, Schiff et al [7] found that even for TSS the maximum concentration does not necessarily occur at the very beginning where $t=0$. This is not as the case as was indicated by the exponential decay function and previous experimental results. Wijesiri et al $[8 ; 9 ; 10]$ further identified that particle size frictions $<150 \mu \mathrm{m}$ predominates pollutant buildup and wash-off processes. A recent experiment conducted by Ali et al [11] showed that the highest fraction conveyed by runoff consisted of fine $(<16 \mu \mathrm{m})$ and medium-sized $(<100 \mu \mathrm{m})$ particles. Some researches extended the experimental studies to particles-bound nutrients [12] and other dissolved pollutants [13]. In a study reported recently, Yuan et al [14] indicated that the ADP's effect on wash-off of predominant particles $(<30 \mu \mathrm{m})$ is strong but weak on organic matters and nitrogen. Most of the above-mentioned researches were summarized and reviewed by Wijesiri et al [15]. Many other researches $[16 ; 17 ; 18 ; 19 ; 20]$ monitored pollutant concentration processes along with urban storm runoffs to look at the first flush phenomenon and so on.

In fact, why ADP affects wash-off process is essentially because ADP affects buildup of pollutants. It is far not clear how different species of pollutants behave differently in the buildup process over an antecedent dry period or in more general, no-wash-off period (NWP). In addition, wash-off dynamics of dissolvable pollutants and microorganisms need to be further understood since usually, these pollutants are just partially particles-bound. Therefore this study is to look at wash-off and buildup dynamics of several conventional dissolvable pollutants and microorganisms including $\mathrm{BOD}_{5}, \mathrm{NH}_{3^{-}}, \mathrm{PO}_{4}{ }^{3-}$ and coliforms. Simulated rainfall experiments were conducted at the sites representing parking lots, restaurants and residential blocks in a typical urban area with different ADPs. Pollutographs for $\mathrm{BOD}_{5}$, $\mathrm{NH}_{3}-\mathrm{N}, \mathrm{PO}_{4}{ }^{3-}-\mathrm{P}$, and coliforms were obtained from the experiment. The daily buildup rates and wash-off coefficients of these pollutants were then found by analysis of the experimental data. The daily rates of buildup were also related to the intensity of human activities in the urban area that is believed to be the origin of the pollutants.

\section{Methodology}

\subsection{Understanding wash-off and buildup dynamics}

To describe wash-off process, the following equation was used by many researchers [2] based on consideration of pollutant mass balance on a unit area of the ground surface

$$
\mathrm{d} P / \mathrm{d} t=-k_{\mathrm{w}} I P
$$

where $P$ is the remaining mass of a pollutant on the ground surface; $I$ is the surface runoff from the unit area that is equivalent to intensity of the rainfall; $t$ is time; $k_{\mathrm{w}}$ is so-called wash-off coefficient by assuming $C=k_{\mathrm{w}} P$, where $C$ is the concentration of the pollutant in the surface runoff. From equation (1) one can also obtain that

$$
\mathrm{d} C / \mathrm{d} t=-k_{\mathrm{w}} I C
$$

In the case where $I$ is a constant, solutions to equation (1) and (2) are

$$
P=P_{\mathrm{B}} \exp \left(-k_{\mathrm{w}} I t\right)
$$


And

$$
C=C_{\mathrm{m}} \exp \left(-k_{\mathrm{w}} I t\right)
$$

respectively, having neglected the initial period over which equation (1) and (2) may not be valid for some pollutants or in some cases. In the above solutions, $P_{\mathrm{B}}$ is the total mass of the pollutant on unit area built up over the dry weather period prior to the rainfall event. $C_{\mathrm{m}}$ is the maximum concentration in the pollutograph.

In general, the pollutant load generated from an impervious area, $A$, should be calculated by

$$
W(t)=\int C(t) Q(t) \mathrm{d} t
$$

where $Q(t)$ is the flow rate of the surface runoff. Neglecting water loss due to interception, depression storage, infiltration and evaporation etc., $Q=I A$ is a constant if $I$ is a constant. Hence equation (4) and (5) give

$$
W(t)=Q \int C(t) \mathrm{d} t=\frac{Q C_{\mathrm{m}}}{k_{\mathrm{w}} I}\left(1-\exp \left(-k_{\mathrm{w}} I t\right)\right)=\frac{A C_{\mathrm{m}}}{k_{\mathrm{w}}}\left(1-\exp \left(-k_{\mathrm{w}} I t\right)\right)
$$

For a unit area, $Q=I$, therefore Equation (6) becomes

$$
W(t)=\frac{C_{\mathrm{m}}}{k_{\mathrm{w}}}\left(1-\exp \left(-k_{\mathrm{w}} I t\right)\right)
$$

An equation similar to above equation was employed earlier by Startor et al [21] in their study on mathematical replication of pollutant wash-off.

For a rainfall with high intensity, when $t \rightarrow \infty$, all available mass of the pollutant on the ground surface, $P_{\mathrm{B}}$, would be washed off, then $W \rightarrow P_{\mathrm{B}}$. This provides the possibility to obtain $P_{\mathrm{B}}$ by wash-off experiment using a heavy shower.

In engineering practice, $P_{\mathrm{B}}$ should be predicted base on buildup dynamics. Again, considering mass balance on a unit area, one can obtain [22]

$$
d P_{B} / d t=P_{\mathrm{I}}-k_{\mathrm{d}} P_{\mathrm{B}}
$$

where $P_{\mathrm{I}}$ is the rate of pollutant input to the unit area and $k_{\mathrm{d}}$ is the constant of first-order erosion rate, assuming that pollutants on ground surface comply with first-order erosion. Solution of equation (8) is

$$
P_{\mathrm{B}}=\left(P_{\mathrm{R}}-\frac{P_{\mathrm{I}}}{k_{\mathrm{d}}}\right) \exp \left(-k_{\mathrm{d}} t_{\mathrm{d}}\right)+\frac{P_{\mathrm{I}}}{k_{\mathrm{d}}}
$$

where $P_{\mathrm{R}}$ is the residual mass of the pollutant at the end of the last wash-off process, and $t_{\mathrm{d}}$ is the no-wash period between two wash-off events.

As is mentioned previously, $P_{\mathrm{I}}$ is pollutant accumulation rate. It is assumed to be proportional to population density, $P_{\mathrm{D}}$, a measurement of intensity of human activities in the concerned urban area, i.e.

$$
P_{I}=\omega P_{D}
$$

where $\omega$ is a proportional constant that can reflect influences of various factors such as land use, mode of urban transportation, street cleaning exercises and so on.

Among the above-discussed equations, equation (7) in various versions has been used in SWMM model [3] and several other models for urban stormwater quality modelling. Since $k_{\mathrm{w}}$ is pollutant specific, experiments are needed to identify values of $k_{\mathrm{w}}$ for various species of pollutants besides the previous studies with certain pollutants. It is noticed that equation (9) is not widely used yet. The reason could be because it involves more parameters to be identified by experimental studies.

\subsection{Experiments}

In this study, simulated rainfalls with a constant intensity and an appropriate duration were employed to wash off concerned pollutants from selected sites of a commercial complex. This commercial complex 
with an $85,654 \mathrm{~m}^{2}$ of paved area, called Seri Complex at Batu Satu, composing of supermarkets, stores, restaurants, hotels, office buildings, residential blocks etc., is a typical urban area in Bandar Seri Begawan, the capital city of Brunei Darussalam. A shower was simply used to generate a simulated rainfall. The intensity of the simulated rainfall and its wetted area were controlled by maintaining the flow rate, $Q$, of the shower and the wetted area of simulated rainfall, $A$, as constants for each experiment. In the experiment, simulated rainfalls consistently covered a circular area of $2.0 \mathrm{~m}$ in diameter with an area of $3.14 \mathrm{~m}^{2}$. The flow rate of the shower was $0.06 \mathrm{~L} / \mathrm{s}$ therefore rainfall intensity was calculated to be 69 $\mathrm{mm} / \mathrm{hr}$. The duration of the simulated rainfalls lasted for 20-25 minutes and hence the density of the rainfall was $23-29 \mathrm{~L} / \mathrm{m}^{2}$. The use of the relatively high intensity of simulated rainfall for the experiments was to ensure that absolutely most part of pollutants mass available on the experiment sites could be washed off in the planned duration so as to obtain $P_{\mathrm{B}}$.

The experiments were carried out at the three locations within the commercial complex which represent restaurants, parking lots and residence sites respectively, all paved with concrete. The sites were so chosen that the surface runoff was concentrated to flow in one direction so as to facilitate sampling downstream. Water samples were taken at every 5 minute intervals and tested in the certificated government laboratory soon after. Then the pollutographs for $\mathrm{BOD}_{5}, \mathrm{NH}_{3}-\mathrm{N}, \mathrm{PO}_{4}{ }^{3-}-\mathrm{P}$, and coliforms were obtained.

The effect of the antecedent dry period was considered for the arrangement of experiments. All simulated rainfall experiments were conducted under dry weather conditions. The first experiment was conducted a day after a natural rainfall, followed by the second experiment 4 days after and the third a further 10 days after. The experiment was repeated at the same selected locations every time. Since a natural rainfall with limited intensity and duration is normally not able to wash off all available masses of pollutants on the ground surfaces [4], in this study it was ensured that the sites were cleaned by the first experiment, therefore the data from the second and third experiment with ADP of 4 days and 10 days, respectively, can be used for buildup dynamics analysis.

Table 1. Measured concentration processes in the runoff

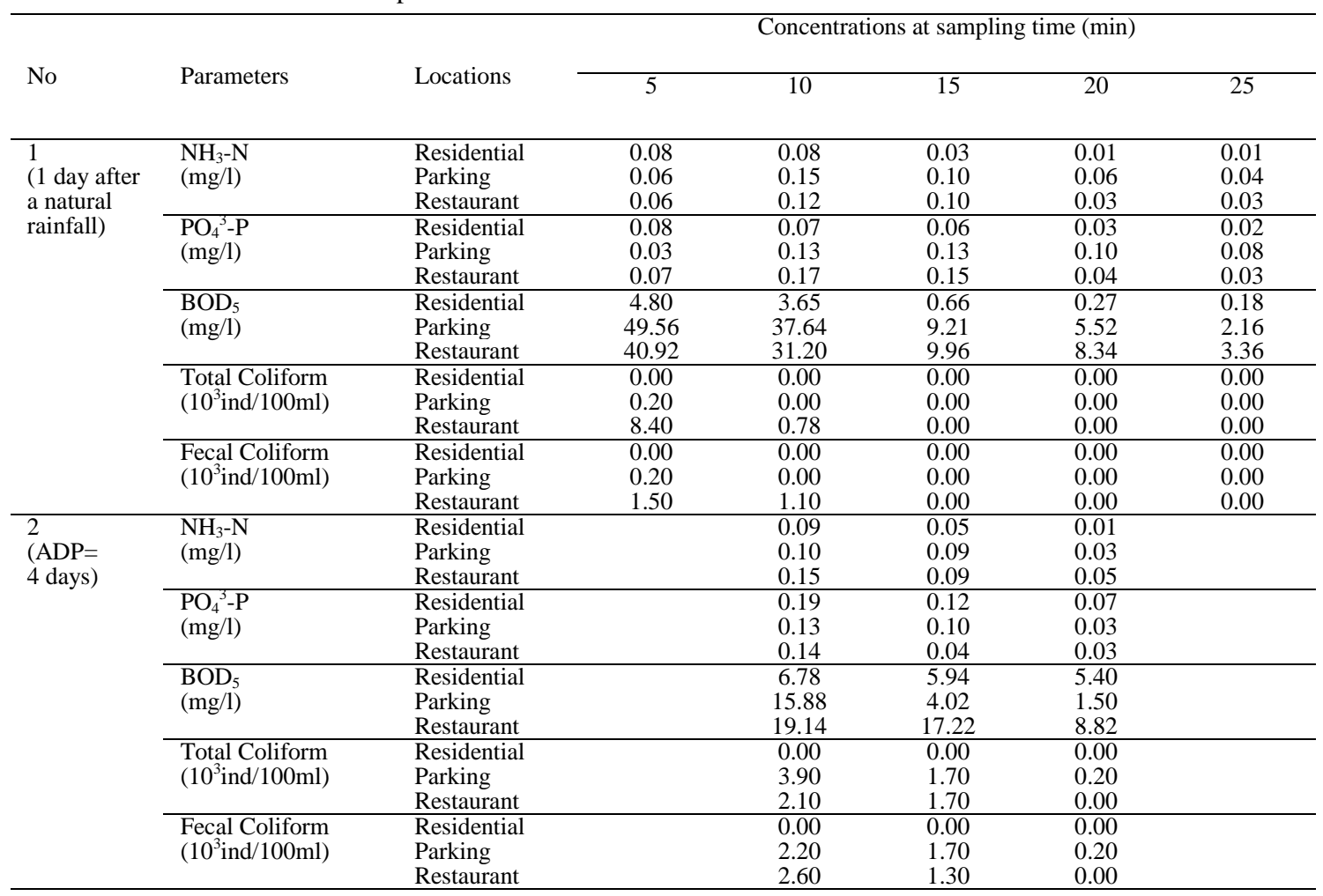




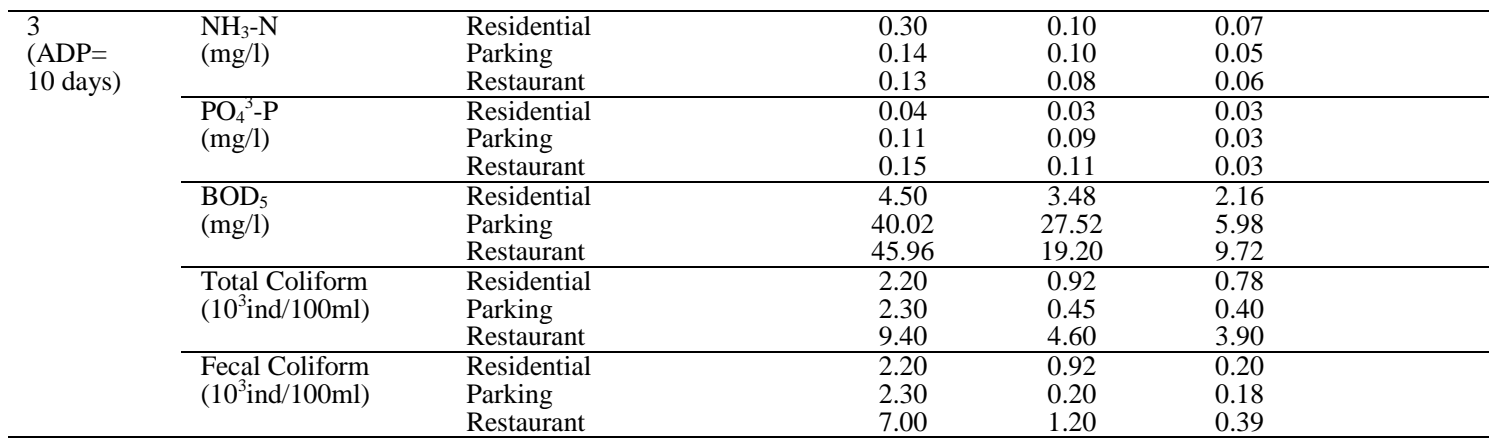

\section{Results and Discussion}

\subsection{Pollutant wash-off}

Table 1 summarizes the experimental data for the five pollutants monitored at the three locations in the three experiments. For cost-effectiveness consideration, only three samples were tested in the second and third experiments. The data indicate that the maximum concentrations of the studied pollutants occur slightly more frequently at the restaurant site, followed by the parking site and then the residential site respectively. However, these random differences cannot lead to a conclusion of which site has more pollutants and others have less. This suggests that the mass of pollutants built up at different locations with different type of land use in the commercial complex are statistically more or less the same. This is because there are close links among human activities with the different type of land use in the area. People move from one place to another frequently, carrying pollutants from one place to another. As a result, the differences of pollutant distributions amongst different land use areas are reduced and become random. This phenomenon was also reported by Miguntanna et al [12] in respect of nutrients buildup. In view of this, pollutographs measured at different sites were averaged for each type of pollutant and the results are plotted in figure 1 . Figure 1 demonstrates that through 25 -minutes wash-off by the simulated rainfall, the residual concentrations in the runoff became very low, meaning that most parts of the pollutant mass on the ground surface were washed off.

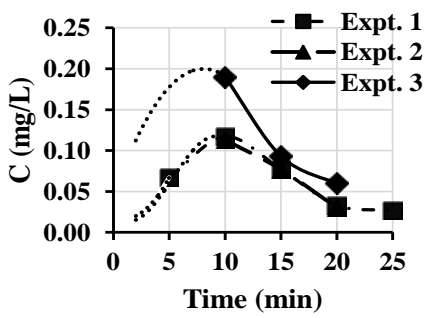

(a) $\mathrm{NH}_{3}-\mathrm{N}$

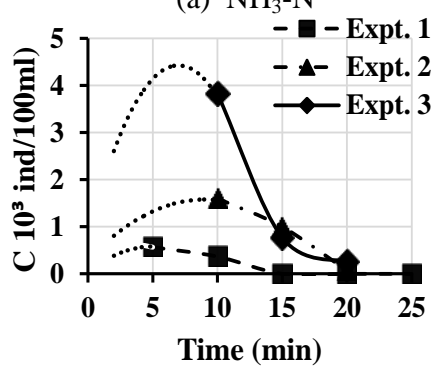

(d) Fecal coliform

Fig. 1. Site-averaged pollutographs

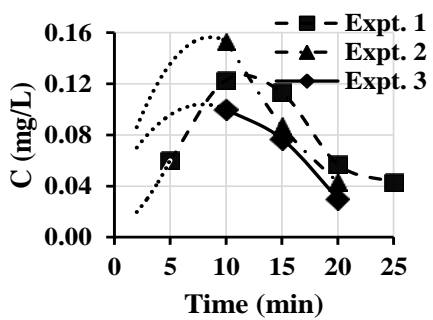

(b) $\mathrm{PO}_{4}{ }^{3-}-\mathrm{P}$

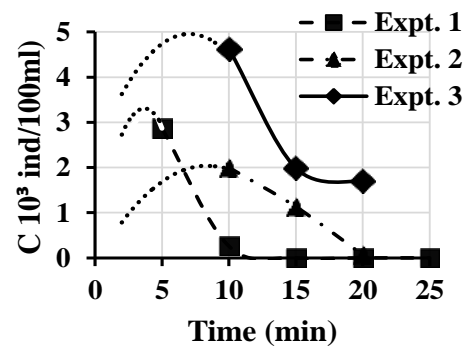

(e) Total coliform

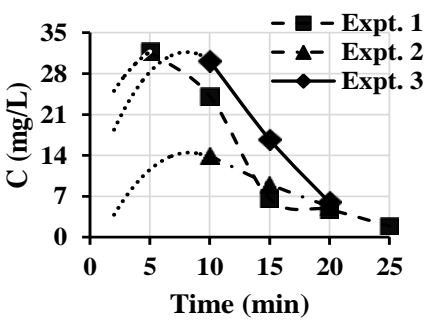

(c) $\mathrm{BOD}_{5}$ 
In view of that the same species of pollutants should follow the same buildup and wash-off dynamics, to better analyze the general wash-off dynamics of organic pollutants, nutrients and coliforms respectively, normalization was implemented to the respective pollutographs of the three species of pollutants in figure 1 . This was done by dividing each pollutograph with the average value of the graph, $C_{\mathrm{A}}$, i.e. event mean concentration (EMC), calculated by [22; 23]

$$
C_{A}=\frac{1}{T} \sum_{1}^{N} C_{i} \Delta t=\frac{\Delta t}{T} \sum_{1}^{N} C_{i}
$$

where, $\Delta t=5$ minutes in this study, $C_{\mathrm{i}}$ is the concentration of $i$-th sample in time series, $N$ is the times of sampling in an experiment, $T=N \Delta t$. The normalized data are plotted in each figure for organic pollutants, nutrients and coliforms, respectively, therefore respective normalized graphs are obtained, as shown in Fig. 2.

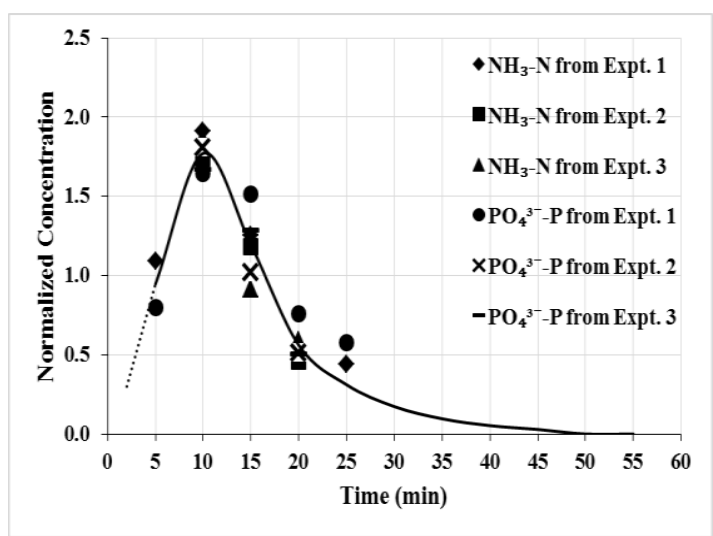

(a) Nutrient

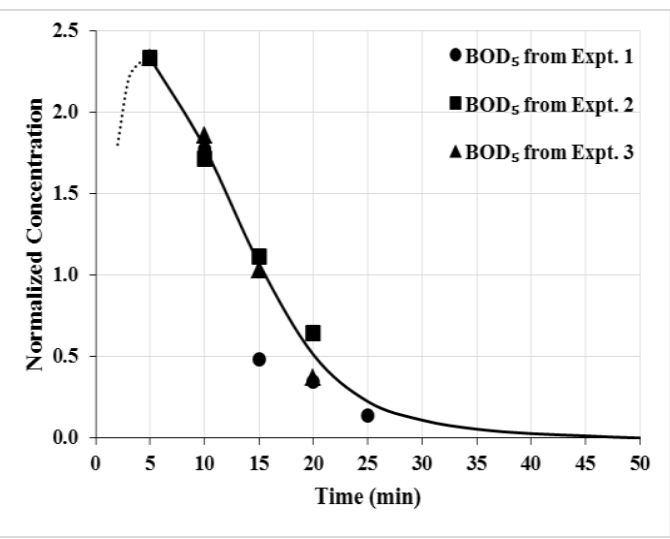

(b) $\mathrm{BOD}_{5}$

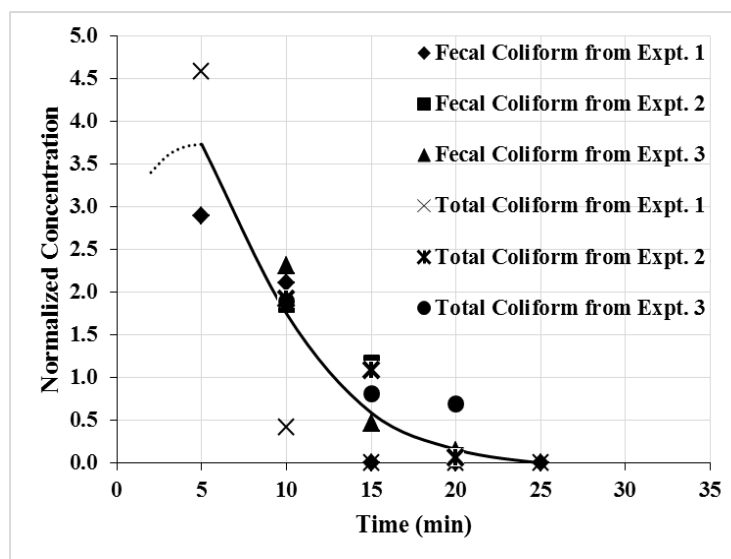

(c) Coliforms

Fig. 2. Best-fit curves of wash-off processes of organic pollutants, nutrients and coliforms

From Fig. 2 one can see that, it is not as what was assumed when obtaining equation (4), the peak concentrations of pollutographs may not all occur at $t=0$. The experiment revealed that peak concentrations of the studied pollutants normally occurred 5 to 10 minutes after the beginning of the rainfall. The time, $t_{\mathrm{m}}$, at which peak concentrations occur should depend on species of pollutants, intensity of rainfall etc. Therefore, equation (4) is applicable to the wash-off process starting at $t=t_{\mathrm{m}}$ and the equation should be modified as 


$$
\frac{C}{C_{A}}=\frac{C_{\mathrm{m}}}{C_{A}} \exp \left[-k_{\mathrm{w}} I\left(t-t_{\mathrm{m}}\right)\right]
$$

The best-fit curves in Fig. 2 give values of wash-off coefficients for the three species of pollutants are listed in Table II. Table II demonstrates that nutrients seem most reluctant to be washed off and coliforms can be washed off most easily. This can be seen also from Fig. 3 which shows that almost 100\% coliforms were washed off in 25 minutes while $90.1 \%$ and $97.9 \%$ for nutrients and organic pollutants, respectively. Fig. 3 were made from Fig. 2 with the assumption that the concentration processes of the three species of pollutants all start from zero. Although the maximum concentrations, rainfall intensity and $t_{\mathrm{m}}$ are also listed in Table II, values of wash-off coefficients should be independent of these factors according to the definition of $k_{\mathrm{w}}$ given by equation (1) and (2). This point agrees with the experimental results for SS reported by Egodawatta et al [4], however Egodawatta et al obtained much smaller washoff coefficients for SS. No experimentally identified values of $k_{\mathrm{w}}$ especially for organic pollutants, nutrients and coliforms were found in previous studies for comparison with the results obtained in this research.

Table 2. Wash-off coefficients of organic pollutants, nutrients and coliforms

\begin{tabular}{lllll}
\hline Pollutant & $C_{\mathrm{m}} / C_{\mathrm{A}}$ & $k \mathrm{w}(1 / \mathrm{mm})$ & $I(\mathrm{~mm} / \mathrm{min})$ & $t_{\mathrm{m}}(\mathrm{min})$ \\
\hline Nutrients & 1.82330 & 0.09543 & 1.15 & 10 \\
BOD5 & 2.47034 & 0.08310 & 1.15 & 5 \\
Coliforms & 3.76648 & 0.14868 & 1.15 & 5 \\
\hline
\end{tabular}
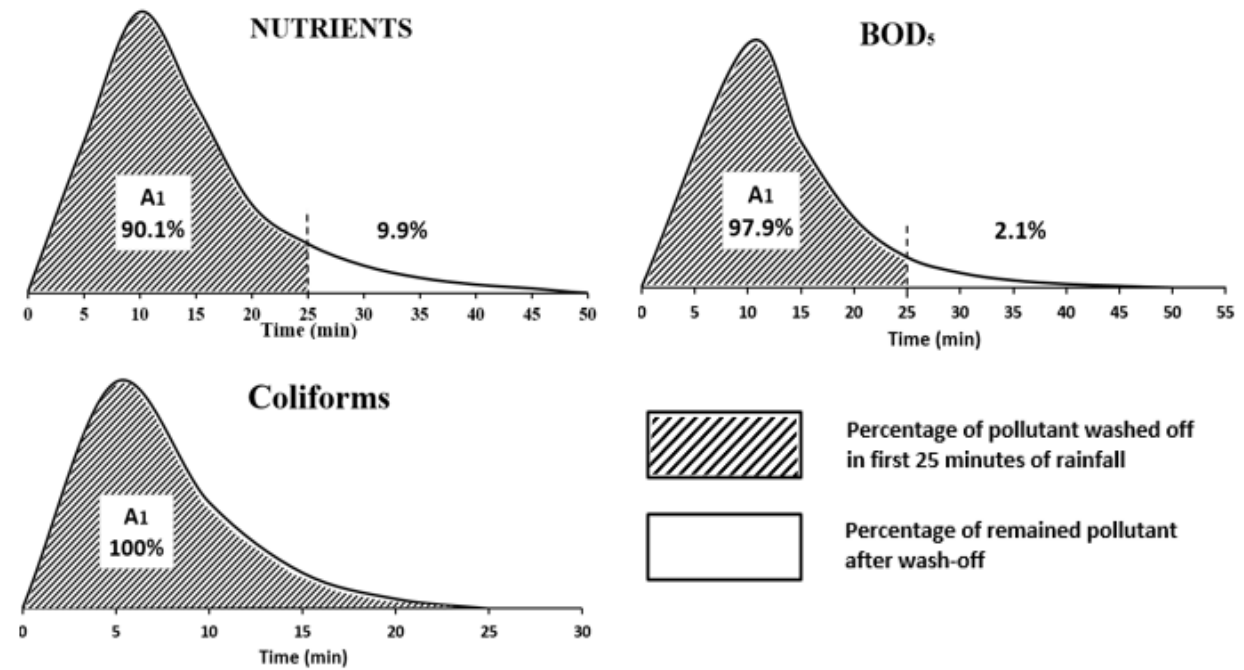

Percentage of pollutant washed off in first 25 minutes of rainfall

Percentage of remained pollutant after wash-off

Fig. 3. Pollutant mass graphs and washed-off percentages in 25 minutes, $\mathrm{A}_{1}$

\subsection{Pollutant buildup}

Based on Fig. 1, the total available mass of pollutants on the site for different antecedent dry periods, $P_{\mathrm{B}}$, were calculated by

$$
P_{\mathrm{B}}=Q C_{A} T=V C_{A}
$$

where, $Q$ and $V$ are the flow rate and the total volume of the simulated rainfall respectively, with the duration, $T$. Values of $P_{\mathrm{B}}$ are listed in Table 3 where masses of ammonia, phosphate and $\mathrm{BOD}_{5}$ at zero antecedent dry day were residual masses at the end of the first experiment. They were estimated by multiplying the masses obtained in the first experiment with the percentages of the remains as were found in Fig. 3. 
Table 3. Site-averaged total masses of pollutants washed off by simulated rainfalls

\begin{tabular}{llllll}
\hline ADP & $\begin{array}{l}\mathrm{NH}_{3} \\
(\mathrm{mg})\end{array}$ & $\begin{array}{l}\mathrm{PO}_{4}{ }^{3-} \\
(\mathrm{mg})\end{array}$ & $\begin{array}{l}\mathrm{BOD}_{5} \\
(\mathrm{mg})\end{array}$ & $\begin{array}{l}\text { Total Coliform } \\
\left(\times 10^{5}\right)\end{array}$ & $\begin{array}{l}\text { Fecal Coliform } \\
\left(\times 10^{5}\right)\end{array}$ \\
\hline 1D after rain & 6.250 & 7.680 & 1559 & 0.778 & 0.215 \\
0D & 0.620 & 0.760 & 32.74 & - & - \\
4D & 5.700 & 7.450 & 797.0 & 1.110 & 0.914 \\
10D & 10.60 & 6.240 & 1885 & 3.091 & 2.101 \\
\hline
\end{tabular}

As is mentioned previously, $P_{\mathrm{B}}$ is the mass of a pollutant built up over the antecedent dry period. Using the data in Table III, the pollutant buildup curves for $\mathrm{BOD}_{5}, \mathrm{NH}_{3}$ - and $\mathrm{PO}_{4}{ }^{3-}$ are plotted in Fig. 4. The parameters in equation (9) given by the theory of least squares are listed in Table IV. Investigation revealed that the population density in the studied commercial complex was $P_{\mathrm{D}}=0.0229$ persons $/ \mathrm{m}^{2}$. With this and $P_{\mathrm{I}}$ values in Table IV, values of $\omega$ in equation (10) are also obtained as is listed in Table IV too.

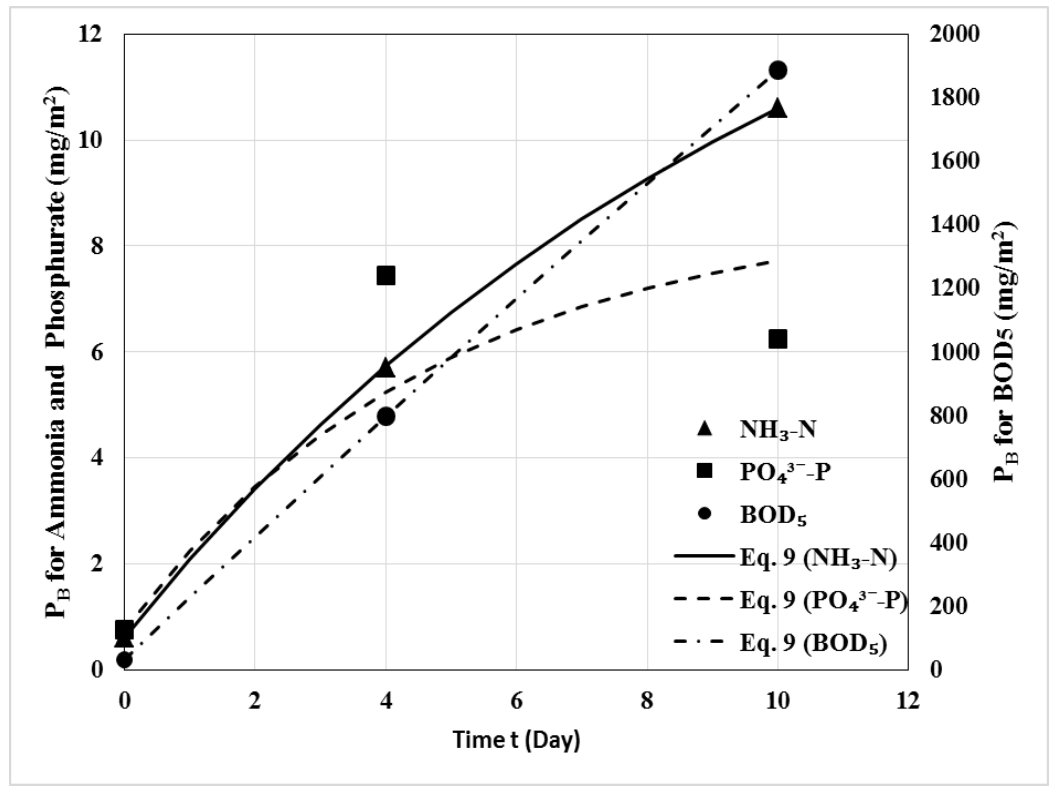

Fig. 4. Pollutant buildup over antecedent dry period

Table 4. Parameters of the buildup equations identified by the experiment

\begin{tabular}{llcc}
\hline Pollutant & $k_{\mathrm{d}}(1 / \mathrm{d})$ & $P_{\mathrm{I}}\left(\mathrm{mg} / \mathrm{m}^{2} /\right.$ day $)$ & $\omega(\mathrm{mg} /$ person/day $)$ \\
\hline BOD $_{5}$ & 0.0105 & 195.5 & 8537 \\
$\mathrm{NH}_{3^{-}}$ & 0.0925 & 1.587 & 69.30 \\
$\mathrm{PO}_{4}{ }^{3-}$ & 0.2063 & 1.801 & 78.65 \\
\hline
\end{tabular}

Like the case regarding wash-off coefficients, no existing experimental result was found in literatures for comparison with the findings listed in Table 4. Nevertheless, if the initial mass of a pollutant, $P_{\mathrm{R}}$, in equation (9) is zero, equation (9) will then become a simpler exponential function that was employed by Wicke et al [6] for mathematical replication of TSS and heavy metals buildup in their research. TSS and heavy metals as conservative materials may even experience erosion during ADP due to wind blow etc., whereas organic pollutants and nutrients may further experience photo-oxidation, volatilization and natural decay etc. over dry days [14]. Integrated impact of these factors determines the $k_{\mathrm{d}}$ value of each type of pollutant as are seen in table 4 as an example. Before additional equations can be developed to describe influences of these factors on pollutant buildup dynamics, many further studies are needed to understand the mechanisms behind it. The experiments by Miguntanna et al [12] showed that the buildup 
of nutrients is associated with the buildup of particles. This result has partly revealed the complicated buildup process of pollutants from one aspect.

The population of coliforms is another conventional and important water quality indicator, particularly in humid tropical areas. The experiment indicated that coliforms grew fast on the ground over the antecedent dry period. Assume the growth of coliforms follows also the logistic growth model

$$
\begin{gathered}
\mathrm{N}=\frac{K}{1+\exp \left[-\beta\left(t-t^{*}\right)\right]} \\
t^{*}=\frac{1}{\beta} \ln \left(\frac{K}{N_{\mathrm{O}}}-1\right) \\
\beta=\frac{R_{\mathrm{O}}}{1-\frac{N_{\mathrm{O}}}{K}}
\end{gathered}
$$

where $N$ is a population of coliforms at time $t ; K$ is the carrying capacity; $\beta$ is the exponential growth rate; $t^{*}$ is the time at which $N$ reaches $K / 2$ from the population $N_{\mathrm{o}}$ at $t=0$ with instantaneous growth rate $\mathrm{R}_{\mathrm{o}}$. Using experimental data in table 3, parameters of the logistic growth model for coliforms growth on the ground are identified and listed in table 5. Considering that coliforms are easily washed off, the data

\begin{tabular}{|c|c|c|c|c|c|}
\hline Parameter & $K\left(\right.$ Ind. $\left./ \mathrm{m}^{2}\right)$ & $\beta\left(\right.$ day $\left.^{-1}\right)$ & $t^{*}$ (day) & $R_{\mathrm{o}}\left(\right.$ day $\left.^{-1}\right)$ & $N_{\mathrm{o}}\left(\right.$ Ind. $\left./ \mathrm{m}^{2}\right)$ \\
\hline Fecal coliforms & $6.90 \times 10^{5}$ & 0.630 & 4.50 & 0.595 & $0.382 \times 10^{5}$ \\
\hline Total coliforms & $9.85 \times 10^{5}$ & 0.360 & 4.07 & 0.290 & $1.85 \times 10^{5}$ \\
\hline
\end{tabular}
obtained in the first experiment has also been used in this analysis.

Table 5. Parameters of logistic growth model for coliforms growth on the ground

As is known, the growth of coliforms needs moisture and energy-contained food. Normally higher natural temperature is more favourable to the growth of bacteria. Therefore, the values of parameters in equation (14) to (16) must depend on humidity, atmospheric temperature and availability of food etc. Without linking these influence factors to the parameters in equation (14) to (16), the values of these parameters listed in table 5 are inevitably site specific.

\section{Conclusion}

The simulated rainfall experiments conducted at different sites representing parking lots, restaurants site and residential blocks in a commercial complex shows that the mass buildup of organic pollutants, nutrients and coliforms are not sensitive to the type of land use but ADP and species of pollutants. This suggests that an urban stormwater quality model may not have to further differentiate the type of land use in the same area.

The experiment revealed that the maximum concentrations of pollutants, $C_{\mathrm{m}}$, may not necessarily occur in the first drop of runoff. Instead, they normally occur between $t=5-10$ minutes after the beginning of the wash-off process. This is particularly true for dissolved pollutants like ammonia and phosphate. Thus, exponential decay function can well replicate pollutographs only from $C=C_{\mathrm{m}}$. This phenomenon requires attention when applying the exponential function in urban stormwater quality models to simulate wash-off processes. Wash-off coefficients ranging from $0.08-0.15 \mathrm{~mm}^{-1}$ respectively for $\mathrm{BOD}_{5}$, nutrients and coliforms are suggested in this study. Values of these wash-off coefficients are independent of rainfall intensity and the total available mass of the pollutants at the beginning of a rainfall event, but may be affected by other factors such as land topography and features of ground surfaces.

Parameters of two typical functions describing pollutant buildup are also identified for $\mathrm{BOD}_{5}$, ammonia, phosphate, fecal and total coliforms respectively, using experimental data obtained in this study. These parameters may be applicable only to the humid tropical areas where the experiment was conducted, as they may depend on local climate conditions, such as sunlight, temperature, humidity and so on. 
Although experiments are usually costly, and more ever, in-situ experiments involve many complicated influence factors that are mostly beyond control and even impose a negative impact on quantity and quality of experiment data, further studies are needed to identify the key sources that contribute to pollutant accumulation and the mechanisms of pollutant erosion over the non-wash-off period.

\section{Acknowledgements}

This study was conducted under research project RNK10 (2012-2017)-1022-1 granted by Brunei Research Council. The Authors sincerely thank Muhammad Khairuddin bin Hj Sarbini, Siti Zuhairah bte Hj Brahim, Siti Ramizah bte Mohd Basri for their major contribution to the experiment.

\section{References}

[1] Novtny V. Non-point pollution and urban stormwater management. Water Quality Management Library. 9, Technomic Publishing Co.; 1995.

[2] Zoppou C. Review of urban storm water models. Environmental Modelling \& Software, 2001; 16: 195-231.

[3] USEPA. Storm Water Management Model User's Manual, Version 5.0, 2004.

[4] Egodawatta P, Thomas E, Goonetilleke A. Mathematical interpretation of pollutant wash-off from urban road surfaces using simulate rainfall. Water Research, 2007; 41: 3025-3031.

[5] Egodawatta P, Thomas E, Goonetilleke A. Understanding the physical processes of pollutant build-up and wash-off on roof surfaces. Science of The Total Environment, 2009; 407: 1834-1841.

[6] Wicke D, Cochrane TA, O'Sulliva AD. Build-up dynamics of heavy metals deposited on impermeable urban surfaces. $J$ Environmental Management, 2012; 113: 347-354.

[7] Schiff KC, Tiefenthaler LL, Bay SM, Greenstein DJ. Effects of rainfall intensity and duration on the first flush from parking lots. Water, 2016; 8(320): 1-10.

[8] Wijesiri B, Egodawatta P, McGree J, Goonetilleke A. Process variability of pollutant build-up on urban road surfaces. Science of The Total Environment, 2015: 518-519: 434-440.

[9] Wijesiri B, Egodawatta P, McGree J, Goonetilleke A. Influence of pollutant build-up on variability in wash-off from urban road surfaces. Science of The Total Environment, 2015; 527-528: 344-350.

[10] Wijesiri B, Egodawatta P, McGree J, Goonetilleke A. Incorporating process variability into stormwater quality modelling. Science of The Total Environment, 2015; 533: 454-461.

[11] Ali SA, Bonhomme C, Dubois P, Chebbo G. Investigation of the wash-off process using an innovative portable rainfall simulator allowing continuous monitoring of flow and turbidity at the urban surface outlet. Science of The Total Environment; 2017; 609: 17-26.

[12] Miguntanna NP, Goonetilleke A, Egodowatta P, Kokot S. Understanding nutrient build-up on urban road surface. $J$ Environmental Sciences, 2010; 22(6): 806-812.

[13] Xiao Y, Zhang T, Liang D, Chen JM. Experimental study of water and dissolved pollutant runoffs on impervious surfaces. $J$ Hydrodynamics B, 2016; 28(1): 162-165.

[14] Yuan Q, Heidi G, Kim Y. An investigation of the relationships between rainfall conditions and pollutant wash-off from the paved road. Water, 2017; 9(4): 1-12.

[15] Wijesiri B, Egodawatta P, McGree J, Goonetilleke A. Understanding the uncertainty associated with particle-bound pollutant build-up and wash-off: a critical review. Water Research, 2016; 101: 582-596.

[16] Gupta K and Saul AJ. Specific relationships for the first flush load in the sewer flows. Water Research, 1996; 30(5): 12441252.

[17] Bertrand-krajewski J, Chebbo G, Saget A. Distribution pollutant mass vs volume in stormwater discharges and the first flush phenomenon. Water Research, 1998; 32(8): 234-256.

[18] Deletic A. The first flush load of urban surface runoff. Water Research, 1998; 32(8): 246-270.

[19] Lee JH, Bang KW, Ketchum LH, Cho JS and Yue MJ. First flush analysis of urban storm runoff. Science of The Total Environment, 2002; 293: 163-175.

[20] Gil K and Im J. Non-point source analysis of a railway bridge area using statistical method: case study of a concrete road bed. J Environmental Sciences, 2014; 26: 1321-1324.

[21] Startor JD, Boyd GB, Agardy FJ. Water Pollution Aspect of Street Surface Contaminants. Research report, No EPA-R272/081. US Environmental Protection Agency, 1974.

[22] Charbeneau RJ and Barretti M. Evaluation of methods for estimating stormwater pollutant loads. Water Environment Research, 1997; 70: 1295-1302.

[23] Sansalone JJ and Buchberger SG. Physical characteristics of urban roadway solids transported during rain events. $J$ Environmental Engineering ASCE, 1998; 123: 134-143. 